\title{
Neuroanatomical correlates of polygenic risk for Parkinson's Disease
}

Nooshin Abbasi ${ }^{1}$, Christina Tremblay ${ }^{1}$, Reza Rajimehr ${ }^{2}$, Eric Yu ${ }^{1,3}$, Ross D Markello ${ }^{1}$, Golia

Shafiei ${ }^{1}$, Nina Khatibi ${ }^{4}$, The ENIGMA-Parkinson's study, Neda Jahanshad ${ }^{5}$, Paul M.

Thompson $^{5}$, Ziv Gan-Or ${ }^{1,3}$, Bratislav Misic ${ }^{1}$, Alain Dagher ${ }^{1}$

1: Montreal Neurological Institute, McGill University, Montreal QC Canada

2: MRC Cognition and Brain Sciences Unit, University of Cambridge, Cambridge, UK

3: Department of Human Genetics, McGill University, Montreal QC Canada

4: Department of Biomedical Engineering, North Tehran Azad University, Tehran, Iran

5: Imaging Genetics Center, Mark and Mary Stevens Neuroimaging \& Informatics Institute, Keck School of Medicine of the University of Southern California, Marina del Rey, California, USA

Corresponding author:

Alain Dagher MD

Montreal Neurological Institute

3801 University St

Montreal QC

Canada H3A 2B4

alain.dagher@mcgill.ca 


\begin{abstract}
Parkinson's Disease (PD) is a progressive neurodegenerative disorder with a long prodromal course. Most cases are sporadic but a polygenic risk score (PRS) recently constructed from genome-wide association studies (GWAS) has identified 90 variants that contribute to disease vulnerability. While some of the genes identified affect known disease pathways, the mechanisms by which genetic risk renders individuals vulnerable remain mostly unknown. Understanding how PD PRS manifests in the brain could inform disease modeling and prevention. Here we use genetic and neuroimaging measures from over 30,000 healthy adults from the UK Biobank to show that PD PRS is associated with cortical thinning in a posterior pattern that significantly overlaps with cortical atrophy seen in PD. We also show that this PD PRS cortical profile overlaps with the distribution of genes associated with excitatory neurons and synaptic signaling, is dependent on anatomical connectivity and on regional expression of the most significant genes from the GWAS, most of which impact the autophagy-lysosomal pathway. Conversely, PD PRS is associated with a global increase in cortical surface area. We discuss potential mechanisms for the effects of genetic risk on cortical thickness and surface area, and suggest that the divergent effects may reflect separate routes of genetic vulnerability.
\end{abstract}




\section{Introduction}

Parkinson's Disease (PD) is a progressive neurodegenerative movement disorder that usually presents after age 50. Age is the greatest risk factor, but there is a long prodromal phase prior to the onset of motor symptoms (Berg et al., 2021). The motor manifestations, bradykinesia, tremor, and rigidity are referred to as "parkinsonism" and are due to loss of dopamine neurons in the substantia nigra pars compacta. However, the pathological process affects the entire central nervous system (Braak et al., 2003), as evidenced by the presence of diffuse brain atrophy even in prodromal and de novo cases (Rahayel et al., 2021b; Zeighami et al., 2015). Most cases of PD are thought to be due to misfolded pathogenic alpha-synuclein, whose accumulations are visible at post-mortem as Lewy bodies and neurites (Brundin and Melki, 2017; Burré et al., 2018; Henderson et al., 2019b). Misfolded alpha-synuclein propagates through the brain via neuronal connections; its accumulation is associated with loss of certain neuronal populations (notably dopamine neurons), but also widespread loss of synapses with an associated diffuse pattern of brain atrophy on MRI (Bellucci et al., 2016; Gcwensa et al., 2021; Laansma et al., 2021; Schulz-Schaeffer, 2010; Zeighami et al., 2015).

Until recently, PD was thought to consist of either rare familial forms or cases of environmental origin. However, there is now clear evidence for more common genetic risk factors even in sporadic cases. Genome-wide association studies (GWAS) have identified numerous genetic variants with small cumulative effects, which can be aggregated into a polygenic risk score (PRS) that may explain up to 36\% of PD heritability (Nalls et al., 2019). Interestingly, many of the genes with rare mutations implicated in monogenic forms of PD also contribute to the polygenic risk. Many of these genes affect inter-related disease mechanisms such as protein homeostasis, autophagy and lysosomal function, and accumulation or clearance of abnormal alpha-synuclein isoforms (Gan-Or et al., 2015; Hou et al., 2020; Senkevich and Gan-Or, 2020). For example, three genes with significant signals in the GWAS are $S N C A$, which encodes alpha-synuclein, $L R R K 2$, whose product is involved in autophagy and lysosomal function and influences alpha-synuclein mediated neurodegeneration (Lin et al., 2009), and $G B A$, which encodes a key lysosomal enzyme implicated in alpha-synuclein degradation (Senkevich and 
Gan-Or, 2020). Mutations in SNCA and LRRK2 genes are also causes of autosomal dominant PD, while $G B A$ mutations are a risk-factor for PD (Gan-Or et al., 2018; Konno et al., 2016). Note however that the function of most genes contributing to the PRS remains unknown. The PD PRS also influences disease severity in individuals with sporadic PD: studies have reported a correlation between PD-PRS and age at onset (Escott-Price et al., 2015), as well as severity of cognitive and motor symptom progression (Paul et al., 2018). An important but unresolved question concerns how the potential risk genes translate into vulnerability to disease. PD likely results from an interaction of genetic, environmental, and stochastic causes. Genetic risk for PD may be associated with a vulnerability to the pathophysiological mechanisms that are associated with PD, mentioned above. This could explain both vulnerability to PD and more severe disease with higher genetic risk. It may be possible to detect evidence of this vulnerability in the brains of healthy older individuals. Therefore, a first goal of the current work was to relate PD-PRS to brain morphometry in healthy adults.

Considerable evidence now supports a model of PD whereby misfolded alpha-synuclein propagates in a prion-like manner along neuronal connections (Henderson et al., 2019a; Luk et al., 2012; Rahayel et al., 2021a). This is reflected in MRI studies in PD showing that neural connectivity shapes the pattern of brain atrophy (Yau et al., 2018; Zeighami et al., 2015; Zheng et al., 2019). We therefore also sought to determine whether any regional brain patterns related to PD-PRS are explainable by brain connectivity.

We used genetic, neuroimaging, and behavioral data from the UK Biobank (UKB) (Sudlow et al., 2015) to uncover the neural and clinical correlates of a genetically determined high-risk state. We first show that the PD-PRS is associated with a pattern of cortical thickness variability that resembles the pattern of atrophy seen in PD patients. We then demonstrate that this pattern is explained by brain connectivity, supporting an underlying propagating process. Moreover, the PD-PRS brain pattern also overlaps spatially with the normal brain expression of the most impactful PD-risk related genes. Surprisingly, we also find that the PD-PRS is associated with greater cortical surface area, affecting the entire cortical mantle. This may suggest divergent causes of genetic vulnerability to PD. 
Finally, we examined certain traits associated with PD to see if any neurobehavioral effects of genetic risk manifest in this population. Considerable evidence supports an association between PD and a reduced tendency for addictive behaviors including cigarette smoking and alcohol intake, sometimes occurring years before motor symptoms (Dagher and Robbins, 2009; Nalls et al., 2019). This has been hypothesized to reflect reduced dopaminergic signaling. There may also be a positive association between PD and intelligence and educational attainment (Fardell et al., 2020). For all these traits the direction and even existence of causal relationships is unclear (Domínguez-Baleón et al., 2021; Grover et al., 2019; Noyce et al., 2019). We therefore asked whether, in the entire UKB sample, there was a relation between these traits and the PD-PRS.

\section{Results}

\section{Genetic and Neuroimaging Data}

We studied brain, genetic, and behavioral data of 31,386 healthy participants aged 45 to 82 years old (mean: 64.3) from the UKB (Miller et al., 2016; Sudlow et al., 2015). We applied the following exclusion criteria: history of bipolar or any neurological disorder including degenerative, vascular, traumatic, and infectious brain pathologies; first degree family history of Parkinson's disease; body mass index $(\mathrm{BMI})>35$; relation to another participant closer than cousin; genetic and self-reported sex mismatch; and non-European ancestry. We calculated PD-PRS by using the R package PRSice2 (Choi and O'Reilly, 2019) with genetic risk data from the largest available Parkinson's disease GWAS meta-analysis (Nalls et al., 2019). For brain morphometry, we used MRI measures of cortical thickness and surface area from parcels of the Desikan-Killiany (DK) atlas (Desikan et al., 2006) as described in (Alfaro-Almagro et al., 2018). We also obtained a thorough list of potential imaging confounds including age, age-squared, sex, head motion in resting and task fMRI, date and date-squared per UKB study site (Alfaro-Almagro et al., 2020). Genotyping batch and the first fifteen genetic principal components, accounting for population ancestry stratification, were also added to the confound list (Neilson et al., 2019). 
We first performed a partial least squares (PLS) analysis (McIntosh and Mišić, 2013), to assess whether a genetic composition of PD-PRS and population ancestry structure is able to explain any degree of variation in cortical thickness and surface area (Fig. 1). PLS is a multivariate approach based on singular value decomposition (SVD) of the data matrices to investigate the linear relationship between two sets of variables. To overcome the effects of the above-mentioned confounds, their contribution was regressed out from the brain maps prior to the PLS analysis. The significance of the covariance explained by each latent variable was obtained from non-parametric permutation testing, and bootstrapping was further employed to obtain a confidence interval for the contribution of each feature to the latent variables. Two significant latent variables were identified for both cortical thickness and surface area, in which the first latent variable was able to explain more than 10\% (Fig. 1a) and 30\% (Fig. 1f) of the variance in the two cortical measures, respectively. Bootstrap testing of latent variable one highlighted a significant and major contribution of PD-PRS in determining the variation in both cortical thickness and surface area (Fig. 1b and 1g). As depicted in Fig. 1b, there was a negative correlation between PD-PRS and cortical thickness, implying that the cortex is thinner with higher genetic risk. Conversely, surface area showed a positive correlation with PD-PRS (Fig. 1g). Thus, a dissociation exists between the effects of genetic risk for PD on cortical thickness and surface area consistent with the previously reported low genetic and phenotypic correlation between the two morphometric measures (Winkler et al., 2010).

Next, to localize the influence of PD-PRS on cortical morphology, we fitted general linear regression models for each cortical region of the DK atlas by considering a regional measurement as the dependent and PD-PRS as the independent variable, while adjusting for the previously mentioned confounds (including age) and correcting for multiple comparisons. We then mapped the t-statistic values of the region-wise analyses for thickness and surface area onto the brain surface for visualization. Consistent with the PLS analyses, PD-PRS showed a negative correlation with cortical thickness (Fig. 1c) and a positive correlation with surface area (Fig. 1h) in several cortical regions. The patterns of variation across the cortex were similar in the two hemispheres for both measurements. Moreover, the correlations seemed relatively greater in the 
more posterior parts of the cortex, particularly for cortical thickness. In order to assess functional correspondence of these patterns, we examined their correlation with seven canonical resting-state functional networks (Yeo et al., 2011). As such, DK parcels with statistically significant influence of PD-PRS on cortical thickness were predominantly located in the posterior part of the brain (Fig. 1d) and had the maximum overlap with the dorsal attention resting-state network followed by the visual network, and the least overlap with the ventral attention network (Fig. 1e). On the other hand, the pattern of significant correlation between surface area and PD-PRS was more widespread, covering almost the entire cortical mantle (Fig. 1h) and also having the maximal overlap with the dorsal attention network (Fig. 1i).

\section{Comparison to Parkinson's disease atrophy distribution}

Next, we asked whether the morphometric effects of the PD-PRS looked like patterns of brain atrophy described in PD. To answer this, we leveraged findings of two recently published, large-scale investigations of PD-specific cortical alterations (Laansma et al., 2021; Tremblay et al., 2021). First, we obtained the PD-specific pattern of atrophy by performing deformation-based morphometry (DBM) in a large sample of PD patients in comparison to healthy controls (Parkinson Progression Marker Initiative, 2011), as described previously (Tremblay et al., 2021). DBM is a measure of the change (expansion or atrophy) in the shape of local brain tissue. Prior studies have shown DBM to be a sensitive measure of brain atrophy in PD (Zeighami et al., 2019, 2015). Hence, we calculated longitudinal changes via DBM in Parkinson's disease after 2 and 4 years of follow up relative to healthy controls. We then performed correlation tests between PD DBM progression maps and our PD-PRS cortical influence maps for thickness and surface area. We used the "spin-tests" method to generate null models that account for the spatial autocorrelation of cortical brain measurements (Markello and Misic, 2021). We observed a significant spatial overlap between the PD-PRS influence on cortical thickness and the PD-specific longitudinal pattern of gray-matter atrophy, at 2 years $(\mathrm{r}=$ 0.37, $\left.\mathrm{p}_{\text {fdr-spin }}<0.005\right)$ and 4 years $\left(\mathrm{r}=0.37, \mathrm{p}_{\text {fdr-spin }}<0.05\right)$ of follow-up (Fig. 2a). In other words, the PD-PRS-related pattern of cortical thickness in healthy participants was found to be spatially correlated with the pattern of cortical thinning in early and more advanced PD patients. We did 
not observe a correspondence between the PD-PRS effects on cortical surface area and brain atrophy in PD.

We also compared the PRS effect maps to those of the ENIGMA consortium, who measured cortical thickness and surface area from T1 MRI scans of 2,367 PD patients and 1,183 healthy controls (Laansma et al., 2021). We observed a positive correlation between the two cortical thickness maps ( $\mathrm{r}=0.37$, pspin $<0.005$, Fig. $2 \mathrm{~b}$ ), meaning that the spatial patterns of reduced cortical thickness related to PD-PRS and to PD itself overlapped. We also observed a negative correlation between the two maps of cortical surface area $(r=-0.4$, pspin $<0.05$, Fig. $2 b)$. This implies that increased cortical surface area related to the PD-PRS maps onto reduced surface area in PD. Interestingly, for both correlations, the effect size increased with greater disease severity (Fig 2c).

\section{Role of connectivity}

In a subsequent analysis, we tested the propagation model. We previously found that the atrophy pattern in PD could be explained by brain connectivity (Zeighami et al., 2015; Zheng et al., 2019), meaning that inter-connected regions tend to covary in their degree of volume loss. We now asked whether white-matter connectivity (measured using diffusion MRI) also influences the PD-PRS related pattern of cortical thickness variability. We observed a significant correlation between regional structural connectivity and the influences of PD-PRS on cortical thickness $(r=$ $\left.0.52, \mathrm{p}_{\mathrm{fdr}-\text { spin }}<0.001\right)$ and surface area $\left(\mathrm{r}=0.9, \mathrm{p}_{\mathrm{fdr}-\mathrm{spin}}<0.001\right)$, while taking spatial autocorrelation into account (Fig. 3a). These correlations imply that interconnected areas tend to have similar PD-PRS related influences on their cortical morphometry.

\section{Comparison to genetic effects on cortical structure}

We then sought to compare the cortical patterns found here with recent descriptions of genetic influence on cortical structure. We made use of a recent GWAS of cortical thickness and surface area in 33,992 individuals (Grasby et al., 2020). This study calculated genetic correlations between cortical structure and several traits including PD. We compared our maps of cortical effects of PD-PRS with the maps of genetic correlation between PD risk and cortical thickness 
and surface area. We averaged cortical values across left and right hemispheres to provide aggregate maps, as was done in the above-mentioned meta-analysis, and then repeated our prior regression models to obtain the PD-PRS influences on these averaged measurements. We next performed correlation analyses between the corresponding t-statistic maps from the meta-analyses and the newly generated maps of PD-PRS influences, while controlling for spatial autocorrelation and multiple comparisons. There was a significant resemblance between the PD-PRS influence on cortical surface area and its shared genetic effects with PD $\left(r=0.32, p_{\text {fdr-spin }}\right.$ $<0.05$ ) (Fig. 3a). For cortical thickness there was a marginal but non-significant correspondence between the two maps $\left(\mathrm{r}=0.25, \mathrm{p}_{\mathrm{fdr}-\mathrm{spin}}>0.05\right)$. Note however that cortical thickness had not shown a shared genetic effect with PD (Grasby et al., 2020).

\section{Comparison to gene expression maps}

We then investigated the cortical expression patterns of the genes near the PD top ten and top twenty most significant single nucleotide polymorphisms (SNP), including $S N C A$, from the PD GWAS study (Nalls et al., 2019). For this purpose, we incorporated gene expression data from the Allen Human Brain Atlas (Hawrylycz et al., 2012). This approach revealed that PD-PRS influences on cortical thickness, but not surface area, overlap with the cortical expression of PD-specific genes (top ten genes $r=0.21, p_{\text {fdr-spin }}<0.05$ - top twenty genes $r=0.19, p_{\text {fdr-spin }}<$ 0.05) (Fig. 3b).

\section{Virtual histology}

Neurodegenerative disorders have been shown to differentially affect certain cell types.

Therefore, we investigated if PD-PRS thickness and surface area maps generated here were associated with the prevalence of specific cell types in the cortex by using a virtual histology approach (see details in Methods and Materials). Four cell types showed an association with both PD-PRS related thickness and surface area maps (Fig. 4). Positive correlations were found between the prevalence of excitatory neurons and PRS effects on cortical thickness $\left(r=0.27\right.$, $p_{\text {fdr }}$ $<0.05)$ and surface area $\left(\mathrm{r}=0.26, \mathrm{p}_{\mathrm{fdr}}<0.05\right)$. Significant negative correlations were also observed between PRS effects and the prevalence of microglia (thickness: $r=-0.32, p_{\text {fdr }}<0.05$; 
surface area: $\mathrm{r}=-0.31, \mathrm{p}_{\mathrm{fdr}}<0.05$ ), oligodendrocyte precursors (thickness: $\mathrm{r}=-0.41, \mathrm{p}_{\mathrm{fdr}}<0.05$;

surface area: $\mathrm{r}=-0.39, \mathrm{p}_{\mathrm{fdr}}<0.05$ ) and astrocytes (thickness: $\mathrm{r}=-0.43, \mathrm{p}_{\mathrm{fdr}}<0.01$ ). No significant correlation was found for the three other cell types (inhibitory neurons, oligodendrocytes, and endothelial cells).

\section{Gene ontology analysis}

Relatedly, to determine the functions of the genes whose expression was spatially associated with PD-PRS related thickness or surface area maps, a gene ontology (GO) enrichment analysis was done. To ensure that the results were not due to the choice of a particular classification system, two platforms, GOrilla and PANTHER, were used (see Methods and Materials). No significant results were associated with surface area. The results associated with cortical thickness from each platform implicated terms related to neuronal signaling. Table 1 presents the significant GO terms from the genes negatively associated with the PD-PRS thickness map using the GOrilla $(n=4)$ and PANTHER $(n=5)$ platforms, and their fold enrichment. The GO enrichment analysis in both platforms revealed processes related to the cell surface receptor signaling pathways (fold enrichment $=1.40$ (GOrilla) and $1.44($ PANTHER $)$ ). In addition, processes related to regulation of signaling (fold enrichment $=1.27$ ), signal transduction $($ fold enrichment $=1.26$ ) and cell communication (fold enrichment $=1.25$ ) from the same set of genes were revealed, using either platform. In other words, cortical regions with more synaptic and signaling activity seem to have greater PD-PRS related cortical thinning. We did not observe a significant GO term for the genes that were positively associated with cortical thickness with either platform. Collectively, these results lend support to the notion that, as with the disease itself, the pattern of PD-PRS related cortical alteration is predominantly associated with synaptic transmission and signaling pathways.

\section{Behavioral correlates of genetic risk for PD}

We exploited the availability of a number of behavioral measures, from a larger sample of UKB to assess their relationship with the PD-PRS (Table 2, Fig. 5). We found significant negative associations between PD-PRS and smoking (packs/year, $\mathrm{n}=134,861, t=-3.48, \mathrm{p}_{\mathrm{fdr}}<0.005$ ), 
frequency of alcohol consumption $\left(\mathrm{n}=142,516, t=-4.08, \mathrm{p}_{\mathrm{fdr}}<0.005\right)$, and body mass index $(\mathrm{n}$ $\left.=448,461, t=-4.01, \mathrm{p}_{\mathrm{fdr}}<0.005\right)$, supporting the notion that PD-related behavioral alterations may develop in healthy subjects with relative PD genetic susceptibility prior to or in the absence of overt PD. There was a positive association between PD-PRS and sleep duration ( $\mathrm{n}=446,714$, $\left.t=2.77, \mathrm{p}_{\mathrm{fdr}}<0.01\right)$. Coffee consumption $(\mathrm{n}=448,360, t=1.04)$, educational attainment $(\mathrm{n}=$ $449,137, t=1.53)$ and fluid intelligence $(\mathrm{n}=147,365, t=1.01)$ did not show a statistically significant association.

\section{Discussion}

We present an investigation of the neural correlates of genetic risk for PD using neuroimaging and genotyping data from 31,386 healthy older individuals. Higher genetic risk was associated with lower cortical thickness in mostly posterior areas and greater cortical surface area globally. A similar dichotomy has also been reported in PD (i.e. increased area, reduced thickness), albeit in a more spatially restricted pattern and in studies with relatively small sample sizes (Gerrits et al., 2016; Jubault et al., 2011). Measures of cortical surface area and thickness from T1-weighted MRI are independent: while both are heritable, they demonstrate little genetic overlap and are thought to result from different neuro-developmental processes (Chen et al., 2013; Grasby et al., 2020; Winkler et al., 2010). This has been linked to the radial-unit hypothesis (Rakic et al., 2009), wherein neural progenitor differentiation in early embryogenesis is reflected in the number of neocortical columns and hence surface area, while events later in development influence the number of neurons and synapses per column and are reflected in cortical thickness (Geschwind and Rakic, 2013). During life, synaptic pruning and age-related neurodegeneration may result in reductions in cortical thickness (Fjell et al., 2015). A GWAS study of cortical morphometry confirmed the ontogenetic dichotomy between thickness and surface area (Grasby et al., 2020): both anatomical features were related to genetic regulatory sites, but surface area was associated with elements active in the mid-fetal period of development while thickness was mostly linked to regulatory activity in adulthood. This suggests that the 
cortical thickness and surface area associations found here may represent different mechanisms of genetic risk for PD.

The regions showing PD-PRS-related cortical thinning were mostly in occipital and parietal lobe, as well as medial and orbital prefrontal areas (Fig. 1). This pattern overlapped significantly with the cortical thinning distribution seen in PD in two large cohorts: ENIGMA (Laansma et al., 2021) and PPMI (Parkinson Progression Marker Initiative, 2011). The associations between PD-PRS and PD cortical thinning were stronger with advanced disease stage (from the ENIGMA study) and matched progressive cortical atrophy patterns after 4 years (in the PPMI dataset). Thus, the genetically-determined cortical thinning pattern corresponds spatially to the progressive neural tissue loss seen in PD: areas showing lower cortical thickness in people with higher genetic risk are the ones that tend to atrophy faster in PD.

The PD-PRS-associated cortical thinning pattern also overlapped with the cortical expression of the most significant associated genes from the GWAS (Nalls et al., 2019). Overlap between patterns of cortical thickness and expression of genes that influence cortical thickness has also been described for normal cortical development (Rakic et al., 2009) and several neurodevelopmental disorders (Seidlitz et al., 2020). Twelve of the top 20 genes from the PD GWAS are associated with the autophagy-lysosomal pathway implicated in protein homeostasis and alpha-synuclein accumulation (Table 3) (Hou et al., 2020; Senkevich and Gan-Or, 2020). Their greater expression in areas affected by the PD-PRS could represent a neurodevelopmental influence, but it could also represent accelerated age-related synaptic loss.

Age-related cortical thinning is thought to be due to loss of neuropil and synaptic density rather than neuronal loss (Bishop et al., 2010; Freeman et al., 2008). Virtual histology approaches based on MRI support the theory that cortical thinning with aging or neurodegeneration reflects loss of dendritic arbors and synapses (Patel et al., 2020; Tremblay et al., 2021; Vidal-Pineiro et al., 
2020). Similarly, postmortem studies show that PD appears to be associated with synaptic loss but normal neuronal numbers in the cortex (McCann et al., 2016; Pedersen et al., 2005). We found a similar result for the PD-PRS related pattern of cortical thinning, namely a relationship to expression of genes involved in synaptic and signaling activities.

Thus, an intriguing possibility is that lower cortical thickness associated with genetic risk for PD in older adults shown here may represent synaptic loss similar to that seen in PD. Indeed, autosomal-lysosomal pathway dysfunction leads to imapired protein homeostasis and alpha-synuclein accumulation at the synapse (Soukup et al., 2018). It is possible that high genetic risk for PD derives in part from an enhanced susceptibility to lysosomal dysfunction, toxic protein accumulation, and synaptic damage in older age, and that these phenomena are apparent in people who do not have overt PD.

In PD, the spatial pattern of cortical atrophy follows anatomical connectivity (Yau et al., 2018; Zeighami et al., 2015), which has been hypothesized to reflect neuronal propagation of alpha-synuclein misfolding (Luk et al., 2012; Zheng et al., 2019). Therefore, if the cortical thickness pattern associated with PD-PRS reflects reduced synaptic density due to similar mechanisms, it may be expected to also follow connectivity. Indeed, this is what we found: the PD-PRS effect on cortical thickness in any region was proportional to the summed effect in its connected neighbors.

It should be noted that there is no evidence that healthy adults with higher genetic risk for PD have a subclinical form of the disease or harbor any PD-like pathology. Moreover, while we found that the most significant genes from the PD-PRS demonstrated an expression pattern (in healthy adult brains) similar to the PD-PRS related cortical thickness pattern, supporting a causal effect, the function of many genes contributing to the PD GWAS remains unknown. Nonetheless, it is interesting to note that a population postmortem study in elderly individuals not diagnosed 
with PD identified the frequent occurrence of Lewy pathology in a distribution that resembled PD (Raunio et al., 2019).

The finding of diffusely increased cortical surface area with higher PD-PRS is in contrast to the reduced cortical thickness. As mentioned earlier, a GWAS study of cortical morphometry in 33,992 individuals supported the theory of divergent genetic contributions to cortical surface area and thickness (Grasby et al., 2020). These authors also found a positive genetic correlation between total cortical surface area and three phenotypes: PD, educational attainment, and cognitive ability. This may be consistent with studies that have identified intelligence and educational attainment as risk factors for PD (Fardell et al., 2020; Frigerio et al., 2005), although in our sample there was no effect of PD-PRS on intelligence or educational attainment. It is not clear why the PD-PRS is associated with increased cortical surface area, but the finding raises the possibility that some of the genetic risk for PD derives from effects on neural progenitors and a consequent increase in cortical surface area. Why a brain with greater cortical surface area, and perhaps neuronal columns, is also vulnerable to PD pathology remains unknown.

Finally, we sought to determine whether people with high PD-PRS also displayed brain-based phenotypes seen in PD. We found that, in the larger UKB sample, PD-PRS is associated with a reduced tendency to smoke or drink alcohol and lower BMI. These associations are also consistently described in PD (Dagher and Robbins, 2009; Nalls et al., 2019; Noyce et al., 2019). While some research has proposed a protective effect of cigarette smoking on the brain, the association found here is more compatible with the opposite causality - namely that genetic predisposition to PD is associated with a reduced tendency for behaviors that depend on reinforcement, namely drug addiction and over-eating. There was also a positive association between PD-PRS and questionnaire-derived sleep duration, which has also been described in PD (Chen et al., 2006). Intelligence and educational attainment did not show a statistically significant association with genetic risk. 
There are some limitations to this study. The PD-PRS only accounts for $16-36 \%$ of the heritability of PD (Nalls et al., 2019), meaning that genetic effects not studied here may also contribute to vulnerability to PD in different ways. Also, the findings are correlative and do not prove a causal relationship between either of the morphometric brain patterns uncovered here and the development of PD. Finally, future studies should investigate MRI measures of basal ganglia and white matter integrity, which are also available in UKB. Nonetheless, our results provide evidence that the genetic risk for PD manifests in the brain of healthy individuals, and that it resembles morphometric changes seen in PD itself. We hope that these findings may be of use in understanding and modeling prodromal PD, potentially important steps in developing neuroprotective interventions.

\section{Materials and Methods}

\section{Data resource}

UK Biobank (UKB) is a large prospective study, covering half a million participants aged between 40-69 at the baseline assessment period (2006-2010). The cohort aims to shed light on the etiology of a wide range of health-related outcomes and further improvement in their prevention, diagnosis, and treatment (Sudlow et al., 2015). UKB encompasses a comprehensive set of information on lifestyle, environment, medical history, physical measures and biological samples. Our study involved data from a subset of 42,488 participants (31,386 after exclusions) with brain-imaging measures of cortical morphology including thickness and surface area (Alfaro-Almagro et al., 2018; Miller et al., 2016). This study was conducted under UKB approvals for application \#35605 (PI Dagher). Participants provided written, informed consent (http://biobank.ctsu.ox.ac.uk/crystal/field.cgi?id=200). Exclusion criteria for the current analysis were a history of bipolar or any neurological disorder including a comprehensive set of degenerative, vascular, traumatic, infectious brain pathologies; first degree family history of Parkinson's disease; body mass index $(\mathrm{BMI})>35$; relation to another participant closer than cousin; genetic and self-reported sex mismatch; and non-European ancestry. The latter criterion 
is necessary at the present time to ensure valid genetic analyses, as the GWAS studies were performed in European ancestry individuals. This study was approved by the McGill University Health Centre Research Ethics Board. Open-access data from listed sources derive from studies that were approved by the relevant local ethics boards.

\section{Data analysis software}

The software packages used for analysis of data in this study included FreeSurfer (http://surfer.nmr.mgh.harvard.edu/), FSL (https://fsl.fmrib.ox.ac.uk/fsl/fslwiki/) and PLINK (Purcell et al., 2007), available at http://pngu.mgh.harvard.edu/purcell/plink/. The analyzed data were imported into MATLAB (The Mathworks, Inc.) and Python (https://www.python.org/) for further computations. Gene expression maps were generated using abagen (https://github.com/rmarkello/abagen).

\section{Brain imaging and preprocessing procedures}

The structural magnetic resonance imaging data were acquired as high-resolution T1-weighted images using a 3D MPRAGE sequence at 1-mm isotropic resolution at three imaging sites in the United Kingdom with identical scanners and acquisition protocols. Data were submitted to automated preprocessing and quality control pipelines (Alfaro-Almagro et al., 2018). For the current analysis, we used cortical thickness and surface area values generated with FreeSurfer and parcellation of the surface using the DK atlas. Data from 42,488 participants of the UKB data release in early 2021 were used. We included data from 31,386 individuals, after applying the exclusion criteria mentioned earlier.

\section{PD-PRS calculation}

We consider the 487,410 samples included in the 2019 release of UKB. Of the samples, 31,386 are included among the 42,488 samples in UKB for which brain imaging data are available, after the genotyping quality control procedures for sample removal (Bycroft et al., 2018). As noted above, we excluded subjects with non-European ancestry based on self-reported ancestry and genetic principal component thresholds. In addition, we excluded individuals based on 
relatedness, closer than cousins, creating a maximally unrelated study sample. Subjects whose self-reported sex information did not match the genotyping were also excluded. The final sample size after all exclusions was 31,386. The PD-PRS was calculated using the effect size of 1805 SNPs from the latest PD GWAS summary statistics (Nalls et al., 2019) using PRSice-2 (Choi and O'Reilly, 2019) without pruning or thresholding. These steps were omitted because the 1805 SNPs were tested by Nalls et al. in a discovery cohort and replicated. Note also that this GWAS included 18,618 first-degree relatives of people with Parkinson's Disease in the UKB, as proxy cases, and that these are excluded from the present analysis.

\section{Confounds}

A comprehensive set of imaging and genetic confounds was defined for further analyses which included age, age squared, sex, head motion during functional MRI, scan date, site and its interactions with the previous confounds (Alfaro-Almagro et al., 2020), the 15 top population genetic principal components (explaining most of the data variance) supplied by UKB, and genotyping batch.

\section{Partial least squares analysis}

Partial least squares (PLS) regression is a multivariate method used for finding the relations between two sets of variables (Krishnan et al., 2011; McIntosh and Mišić, 2013). The analysis tries to find linear combinations of the input features that maximally covary with each other. Here, the two variable sets were cortical thickness and surface area, on the one hand, and genetic components including the PD-PRS and 15 top genetic ancestry components, on the other. This analysis was performed to determine whether a combination of genetic factors, and in particular, the PD-PRS, can explain any degree of variation in the brain cortical measurements. For this purpose, we initially regressed out imaging-related confounds (described above) from the brain MRI measurements. Singular value decomposition was then applied to the correlation matrix between the brain and genetic data. We used permutation tests with 500 repetitions to determine the significance of the covariance explained for each latent variable. We then used the 
bootstrapping method (i.e., random resampling with replacement, $n=500$ times) to calculate the confidence interval for individual coefficients for each variable loaded in a given latent variable.

\section{Linear regression models}

Our second analysis involved performing several regression models for each cortical measurement separately, in order to localise the spatial relationship between PD-PRS and cortical surface area and thickness. We again included all the confounders mentioned earlier as covariates in our regression models. P-values were then corrected for multiple comparisons using the false discovery rate (FDR) approach over the number of brain measures. We took $\mathrm{p}=0.05$ (corrected) as the significance threshold.

\section{Correspondences between two cortical maps}

To identify correspondences between the topographies of any two cortical maps, we performed several correlation tests. As most standard methods for statistical inference do not account for spatial properties of the underlying brain maps, we used a spherical projection null model, or spin-test, that permutes cortical regions and generates null distributions while preserving spatial autocorrelation (Markello and Misic, 2021). This model overcomes data loss caused by rotation of the medial wall (containing no data) into the cortical surface by assigning the nearest data to the missing parcels. The statistical significance of each test was assessed and reported against the null distributions from 1,000 repetitions of the spin test (i.e., $\mathrm{p}_{\text {spin }}$ ).

\section{Connectivity Analysis}

To test whether cortical measures in any area were influenced by the same measure in connected neighbors we used structural connectivity data from diffusion MRI in an independent sample of 70 healthy participants (Griffa et al., 2019), as described previously (Shafiei et al., 2020; Tremblay et al., 2021). A deterministic connectivity matrix was built from the normalized number of streamlines between each region pair divided by the average length of the streamlines and the surface area of the two regions. Correlations were computed between the cortical thickness or surface area in each region and its collective neighborhood thickness or surface area, 
defined as the mean value in all connected regions divided by the number of connected regions. Statistical significance was tested against a null model preserving spatial autocorrelation, as described in the previous paragraph.

\section{Cell type analysis: virtual histology}

We investigated if spatial patterns of PD-PRS-related cortical thickness and surface area effects were associated with the relative distribution of specific cell types in the cortex, notably astrocytes, endothelial cells, microglia, excitatory and inhibitory neurons, oligodendrocytes and oligodendrocyte precursors (Shin et al., 2018). Each cell type was associated with its corresponding gene list, as derived by Seidlitz et al. (Seidlitz et al., 2020) from post-mortem single-cell RNA sequencing studies of human cortical samples. The spatial patterns of expression of the genes on each list were then computed using post-mortem gene-expression data from the Allen Human Brain Atlas (Hawrylycz et al., 2012) using the abagen toolbox (https://github.com/rmarkello/abagen) (Arnatkeviciute et al., 2019; Markello et al., 2020). Pearson's correlations were calculated between the thickness or surface area measurement of each region of PD-PRS-related cortical maps and the region's average gene expression of each cell class. All the correlations were corrected for multiple comparisons and were also tested against the nulls obtained from the spin test $\left(\mathrm{p}_{\text {fdr-spin }}\right)$ (Vázquez-Rodríguez et al., 2019). The protocol used here is detailed in Hansen et al. (Hansen et al., 2021).

\section{Gene expression and gene ontology enrichment analysis}

We selected the top ten and top twenty most influential genes in the meta-analysis of PD GWAS (Nalls et al., 2019). The selected genes were those in closest proximity to single nucleotide polymorphisms with the highest contribution in the GWAS, determined on the basis of p-value. We then generated cortical expression maps for these genes by using the gene expression data from the Allen Human Brain Atlas (Hawrylycz et al., 2012) and the abagen toolbox (Markello et al., 2020). The Allen atlas consists of microarray gene expression measurements from 6 donor brains sampled at 500 sites per hemisphere. We compared these spatial gene expression patterns 
to the PD-PRS related patterns while controlling for spatial autocorrelation (Markello and Misic, 2021).

Separately, a gene ontology (GO) enrichment analysis was performed to explore the biological processes related to gene expression from the spatial patterns of PD-PRS influence on cortical thickness and surface area. We extracted the average gene expression value for all genes available in the Allen Human Brain Atlas genetics dataset for each of the cortical regions of the DK atlas using the abagen toolbox. We only retained the genes whose expression significantly correlated with the pattern of PD-PRS related cortical measures after the FDR and spatial auto-correlation corrections. These yielded lists of genes whose expression pattern was positively or negatively correlated with thickness (positive correlation $n=1,065$ genes, negative correlation $\mathrm{n}=1,194$ genes) and surface area (positive correlation $\mathrm{n}=34$ genes, negative correlation $\mathrm{n}=75$ genes) PD-PRS-related maps. We next investigated if the proportion of the GO terms for these genes significantly differed from the proportion of GO terms found for all genes from the dataset. Two gene ontology platforms were used to obtain GO terms, the Gene Ontology enRIchment anaLysis and visuaLizAtion tool (Gorilla) (Eden et al., 2009) and the PANTHER Classification System (Mi et al., 2013). Of the 15,633 genes available in the Allen Human Brain Atlas genetics dataset, 13,992 and 14,657 genes were associated with a GO term in the GOrilla (GO Process) and PANTHER (GO biological process) platforms, respectively. Supported gene IDs are available from the GOrilla (http://cbl-gorilla.cs.technion.ac.il) and PANTHER (www.pantherdb.org) websites. For both platforms, a statistical over-representation analysis was conducted with Bonferroni correction to control for multiple comparisons. Whereas a hypergeometric model was implemented in GOrilla, the Fisher's Exact test was used in PANTHER.

\section{PD-PRS and PD behavioral characteristics}

We asked whether PD-PRS relates to a number of previously identified characteristic phenotypes observed in PD. For this, we included any neurologically healthy participant from UKB with data for the following traits: pack/year of cigarette smoking (if ever done), alcohol intake frequency (daily or almost daily, three or four times a week, once or twice a week, three times a 
month, social occasions only, or never), coffee intake (number of cups per day), sleep duration (hours of sleeping including daily naps per day), educational attainment (defined as: college or university degree, A levels/AS levels or equivalent, O levels/GCSEs or equivalent, CSEs or equivalent, NVQ or HND or HNC or equivalent, other professional qualifications, e.g., nursing, teaching, or none), measured body mass index (BMI; $\mathrm{kg} / \mathrm{m}^{2}$ ) and measured fluid intelligence (the capacity to solve problems that require logic and reasoning ability, independent of acquired knowledge). Subjects with a positive history of neurological or psychiatric disorders (as listed earlier in our exclusion criteria) and/or family history of first-degree PD relatives were excluded from this analysis. We calculated PD-PRS for each participant and then ran linear regression analysis between each behavioral feature and the PD-PRS, while controlling for the effect of age, sex, and the first 15 genetic ancestry principal components. FDR correction was further applied on the p-values to correct for multiple comparisons. Sample sizes for this analysis varied between 130,000 and 450,000 and are listed for each measure in the results section.

\section{Data Availability}

The brain maps of cortical thickness and surface area correlation with PD-PRS will be made available upon request.

\section{Acknowledgements}

This work was funded by grants from the Canadian Institutes of Health Research, the Michael J Fox Foundation for Parkinson's Research, the Alzheimer's Association, the Weston Brain Institute, and the Healthy Brains for Healthy Lives (HBHL) initiative of McGill University. NA received a scholarship from the Montreal Neurological Institute.

We thank Ysbrand van der Werf and Max Laansma for sharing the Enigma maps and for comments on the manuscript.

\section{References}

Alfaro-Almagro F, Jenkinson M, Bangerter NK, Andersson JLR, Griffanti L, Douaud G, Sotiropoulos SN, Jbabdi S, Hernandez-Fernandez M, Vallee E, Vidaurre D, Webster M, McCarthy P, Rorden C, Daducci A, Alexander DC, Zhang H, Dragonu I, Matthews PM, Miller KL, Smith SM. 2018. Image 
processing and Quality Control for the first 10,000 brain imaging datasets from UK Biobank. Neuroimage 166:400-424.

Alfaro-Almagro F, McCarthy P, Afyouni S, Anderson JLR, Bastiani M, Miller KL, Nichols TE, Smith SM. 2020. Confound modelling in UK Biobank brain imaging. bioRxiv. doi:10.1101/2020.03.11.987693

Arnatkeviciute A, Fulcher BD, Fornito A. 2019. A practical guide to linking brain-wide gene expression and neuroimaging data. Neuroimage 189:353-367.

Bellucci A, Mercuri NB, Venneri A, Faustini G, Longhena F, Pizzi M, Missale C, Spano P. 2016. Review: Parkinson's disease: from synaptic loss to connectome dysfunction. Neuropathol Appl Neurobiol 42:77-94.

Berg D, Borghammer P, Fereshtehnejad S-M, Heinzel S, Horsager J, Schaeffer E, Postuma RB. 2021. Prodromal Parkinson disease subtypes - key to understanding heterogeneity. Nat Rev Neurol 17:349-361.

Bishop NA, Lu T, Yankner BA. 2010. Neural mechanisms of ageing and cognitive decline. Nature 464:529-535.

Braak H, Del Tredici K, Rüb U, de Vos RAI, Jansen Steur ENH, Braak E. 2003. Staging of brain pathology related to sporadic Parkinson's disease. Neurobiol Aging 24:197-211.

Brundin P, Melki R. 2017. Prying into the Prion Hypothesis for Parkinson's Disease. J Neurosci 37:9808-9818.

Burré J, Sharma M, Südhof TC. 2018. Cell Biology and Pathophysiology of $\alpha$-Synuclein. Cold Spring Harb Perspect Med 8. doi:10.1101/cshperspect.a024091

Bycroft C, Freeman C, Petkova D, Band G, Elliott LT, Sharp K, Motyer A, Vukcevic D, Delaneau O, O'Connell J, Cortes A, Welsh S, Young A, Effingham M, McVean G, Leslie S, Allen N, Donnelly P, Marchini J. 2018. The UK Biobank resource with deep phenotyping and genomic data. Nature 562:203-209.

Chen C-H, Fiecas M, Gutiérrez ED, Panizzon MS, Eyler LT, Vuoksimaa E, Thompson WK, Fennema-Notestine C, Hagler DJ Jr, Jernigan TL, Neale MC, Franz CE, Lyons MJ, Fischl B, Tsuang MT, Dale AM, Kremen WS. 2013. Genetic topography of brain morphology. Proc Natl Acad Sci US A 110:17089-17094.

Chen H, Schernhammer E, Schwarzschild MA, Ascherio A. 2006. A prospective study of night shift work, sleep duration, and risk of Parkinson's disease. Am J Epidemiol 163:726-730.

Choi SW, O’Reilly PF. 2019. PRSice-2: Polygenic Risk Score software for biobank-scale data. Gigascience 8. doi:10.1093/gigascience/giz082

Dagher A, Robbins TW. 2009. Personality, addiction, dopamine: insights from Parkinson's disease. Neuron 61:502-510.

Desikan RS, Ségonne F, Fischl B, Quinn BT, Dickerson BC, Blacker D, Buckner RL, Dale AM, Maguire RP, Hyman BT, Albert MS, Killiany RJ. 2006. An automated labeling system for subdividing the human cerebral cortex on MRI scans into gyral based regions of interest. Neuroimage 31:968-980.

Domínguez-Baleón C, Ong J-S, Scherzer CR, Rentería ME, Dong X. 2021. Understanding the effect of smoking and drinking behavior on Parkinson's disease risk: a Mendelian randomization study. Sci Rep 11:13980.

Eden E, Navon R, Steinfeld I, Lipson D, Yakhini Z. 2009. GOrilla: a tool for discovery and visualization of enriched GO terms in ranked gene lists. BMC Bioinformatics 10:48.

Escott-Price V, International Parkinson's Disease Genomics Consortium, Nalls MA, Morris HR, Lubbe S, Brice A, Gasser T, Heutink P, Wood NW, Hardy J, Singleton AB, Williams NM, IPDGC consortium members. 2015. Polygenic risk of Parkinson disease is correlated with disease age at onset. Ann Neurol 77:582-591.

Fardell C, Torén K, Schiöler L, Nissbrandt H, Åberg M. 2020. High IQ in Early Adulthood Is Associated 
with Parkinson's Disease. J Parkinsons Dis 10:1649-1656.

Fjell AM, Grydeland H, Krogsrud SK, Amlien I, Rohani DA, Ferschmann L, Storsve AB, Tamnes CK, Sala-Llonch R, Due-Tønnessen P, Bjørnerud A, Sølsnes AE, Håberg AK, Skranes J, Bartsch H, Chen C-H, Thompson WK, Panizzon MS, Kremen WS, Dale AM, Walhovd KB. 2015. Development and aging of cortical thickness correspond to genetic organization patterns. Proc Natl Acad Sci U S A 112:15462-15467.

Freeman SH, Kandel R, Cruz L, Rozkalne A, Newell K, Frosch MP, Hedley-Whyte ET, Locascio JJ, Lipsitz LA, Hyman BT. 2008. Preservation of neuronal number despite age-related cortical brain atrophy in elderly subjects without Alzheimer disease. J Neuropathol Exp Neurol 67:1205-1212.

Frigerio R, Elbaz A, Sanft KR, Peterson BJ, Bower JH, Ahlskog JE, Grossardt BR, de Andrade M, Maraganore DM, Rocca WA. 2005. Education and occupations preceding Parkinson disease: a population-based case-control study. Neurology 65:1575-1583.

Gan-Or Z, Dion PA, Rouleau GA. 2015. Genetic perspective on the role of the autophagy-lysosome pathway in Parkinson disease. Autophagy 11:1443-1457.

Gan-Or Z, Liong C, Alcalay RN. 2018. GBA-Associated Parkinson's Disease and Other Synucleinopathies. Curr Neurol Neurosci Rep 18:44.

Gcwensa NZ, Russell DL, Cowell RM, Volpicelli-Daley LA. 2021. Molecular Mechanisms Underlying Synaptic and Axon Degeneration in Parkinson's Disease. Front Cell Neurosci 15:626128.

Gerrits NJHM, van Loenhoud AC, van den Berg SF, Berendse HW, Foncke EMJ, Klein M, Stoffers D, van der Werf YD, van den Heuvel OA. 2016. Cortical Thickness, Surface Area and Subcortical Volume Differentially Contribute to Cognitive Heterogeneity in Parkinson's Disease. PLoS One 11:e0148852.

Geschwind DH, Rakic P. 2013. Cortical evolution: judge the brain by its cover. Neuron 80:633-647.

Grasby KL, Jahanshad N, Painter JN, Colodro-Conde L, Bralten J, Hibar DP, Lind PA, Pizzagalli F, Ching CRK, McMahon MAB, Shatokhina N, Zsembik LCP, Thomopoulos SI, Zhu AH, Strike LT, Agartz I, Alhusaini S, Almeida MAA, Alnæs D, Amlien IK, Andersson M, Ard T, Armstrong NJ, Ashley-Koch A, Atkins JR, Bernard M, Brouwer RM, Buimer EEL, Bülow R, Bürger C, Cannon DM, Chakravarty M, Chen Q, Cheung JW, Couvy-Duchesne B, Dale AM, Dalvie S, de Araujo TK, de Zubicaray GI, de Zwarte SMC, den Braber A, Doan NT, Dohm K, Ehrlich S, Engelbrecht H-R, Erk S, Fan CC, Fedko IO, Foley SF, Ford JM, Fukunaga M, Garrett ME, Ge T, Giddaluru S, Goldman AL, Green MJ, Groenewold NA, Grotegerd D, Gurholt TP, Gutman BA, Hansell NK, Harris MA, Harrison MB, Haswell CC, Hauser M, Herms S, Heslenfeld DJ, Ho NF, Hoehn D, Hoffmann P, Holleran L, Hoogman M, Hottenga J-J, Ikeda M, Janowitz D, Jansen IE, Jia T, Jockwitz C, Kanai R, Karama S, Kasperaviciute D, Kaufmann T, Kelly S, Kikuchi M, Klein M, Knapp M, Knodt AR, Krämer B, Lam M, Lancaster TM, Lee PH, Lett TA, Lewis LB, Lopes-Cendes I, Luciano M, Macciardi F, Marquand AF, Mathias SR, Melzer TR, Milaneschi Y, Mirza-Schreiber N, Moreira JCV, Mühleisen TW, Müller-Myhsok B, Najt P, Nakahara S, Nho K, Olde Loohuis LM, Orfanos DP, Pearson JF, Pitcher TL, Pütz B, Quidé Y, Ragothaman A, Rashid FM, Reay WR, Redlich R, Reinbold CS, Repple J, Richard G, Riedel BC, Risacher SL, Rocha CS, Mota NR, Salminen L, Saremi A, Saykin AJ, Schlag F, Schmaal L, Schofield PR, Secolin R, Shapland CY, Shen L, Shin J, Shumskaya E, Sønderby IE, Sprooten E, Tansey KE, Teumer A, Thalamuthu A, Tordesillas-Gutiérrez D, Turner JA, Uhlmann A, Vallerga CL, van der Meer D, van Donkelaar MMJ, van Eijk L, van Erp TGM, van Haren NEM, van Rooij D, van Tol M-J, Veldink JH, Verhoef E, Walton E, Wang M, Wang Y, Wardlaw JM, Wen W, Westlye LT, Whelan CD, Witt SH, Wittfeld K, Wolf C, Wolfers T, Wu JQ, Yasuda CL, Zaremba D, Zhang Z, Zwiers MP, Artiges E, Assareh AA, Ayesa-Arriola R, Belger A, Brandt CL, Brown GG, Cichon S, Curran JE, Davies GE, Degenhardt F, Dennis MF, Dietsche B, Djurovic S, Doherty CP, Espiritu R, Garijo D, Gil Y, Gowland PA, Green RC, Häusler AN, Heindel W, Ho B-C, Hoffmann WU, Holsboer F, Homuth G, Hosten N, Jack CR Jr, 
Jang M, Jansen A, Kimbrel NA, Kolskår K, Koops S, Krug A, Lim KO, Luykx JJ, Mathalon DH, Mather KA, Mattay VS, Matthews S, Mayoral Van Son J, McEwen SC, Melle I, Morris DW, Mueller BA, Nauck M, Nordvik JE, Nöthen MM, O’Leary DS, Opel N, Martinot M-LP, Pike GB, Preda A, Quinlan EB, Rasser PE, Ratnakar V, Reppermund S, Steen VM, Tooney PA, Torres FR, Veltman DJ, Voyvodic JT, Whelan R, White T, Yamamori H, Adams HHH, Bis JC, Debette S, Decarli C, Fornage M, Gudnason V, Hofer E, Ikram MA, Launer L, Longstreth WT, Lopez OL, Mazoyer B, Mosley TH, Roshchupkin GV, Satizabal CL, Schmidt R, Seshadri S, Yang Q, Alzheimer's Disease Neuroimaging Initiative, CHARGE Consortium, EPIGEN Consortium, IMAGEN Consortium, SYS Consortium, Parkinson's Progression Markers Initiative, Alvim MKM, Ames D, Anderson TJ, Andreassen OA, Arias-Vasquez A, Bastin ME, Baune BT, Beckham JC, Blangero J, Boomsma DI, Brodaty H, Brunner HG, Buckner RL, Buitelaar JK, Bustillo JR, Cahn W, Cairns MJ, Calhoun V, Carr VJ, Caseras X, Caspers S, Cavalleri GL, Cendes F, Corvin A, Crespo-Facorro B, Dalrymple-Alford JC, Dannlowski U, de Geus EJC, Deary IJ, Delanty N, Depondt C, Desrivières S, Donohoe G, Espeseth T, Fernández G, Fisher SE, Flor H, Forstner AJ, Francks C, Franke B, Glahn DC, Gollub RL, Grabe HJ, Gruber O, Håberg AK, Hariri AR, Hartman CA, Hashimoto R, Heinz A, Henskens FA, Hillegers MHJ, Hoekstra PJ, Holmes AJ, Hong LE, Hopkins WD, Hulshoff Pol HE, Jernigan TL, Jönsson EG, Kahn RS, Kennedy MA, Kircher TTJ, Kochunov P, Kwok JBJ, Le Hellard S, Loughland CM, Martin NG, Martinot J-L, McDonald C, McMahon KL, Meyer-Lindenberg A, Michie PT, Morey RA, Mowry B, Nyberg L, Oosterlaan J, Ophoff RA, Pantelis C, Paus T, Pausova Z, Penninx BWJH, Polderman TJC, Posthuma D, Rietschel M, Roffman JL, Rowland LM, Sachdev PS, Sämann PG, Schall U, Schumann G, Scott RJ, Sim K, Sisodiya SM, Smoller JW, Sommer IE, St Pourcain B, Stein DJ, Toga AW, Trollor JN, Van der Wee NJA, van 't Ent D, Völzke H, Walter H, Weber B, Weinberger DR, Wright MJ, Zhou J, Stein JL, Thompson PM, Medland SE, Enhancing NeuroImaging Genetics through Meta-Analysis Consortium (ENIGMA) - Genetics working group. 2020. The genetic architecture of the human cerebral cortex. Science 367. doi:10.1126/science.aay6690

Griffa A, Alemán-Gómez Y, Hagmann P. 2019. Structural and functional connectome from 70 young healthy adults. doi:10.5281/zenodo.2872624

Grover S, Lill CM, Kasten M, Klein C, Del Greco M F, König IR. 2019. Risky behaviors and Parkinson disease: A mendelian randomization study. Neurology 93:e1412-e1424.

Hansen JY, Markello RD, Vogel JW, Seidlitz J, Bzdok D, Misic B. 2021. Mapping gene transcription and neurocognition across human neocortex. Nat Hum Behav. doi:10.1038/s41562-021-01082-z

Hawrylycz MJ, Lein ES, Guillozet-Bongaarts AL, Shen EH, Ng L, Miller JA, van de Lagemaat LN, Smith KA, Ebbert A, Riley ZL, Abajian C, Beckmann CF, Bernard A, Bertagnolli D, Boe AF, Cartagena PM, Chakravarty MM, Chapin M, Chong J, Dalley RA, David Daly B, Dang C, Datta S, Dee N, Dolbeare TA, Faber V, Feng D, Fowler DR, Goldy J, Gregor BW, Haradon Z, Haynor DR, Hohmann JG, Horvath S, Howard RE, Jeromin A, Jochim JM, Kinnunen M, Lau C, Lazarz ET, Lee C, Lemon TA, Li L, Li Y, Morris JA, Overly CC, Parker PD, Parry SE, Reding M, Royall JJ, Schulkin J, Sequeira PA, Slaughterbeck CR, Smith SC, Sodt AJ, Sunkin SM, Swanson BE, Vawter MP, Williams D, Wohnoutka P, Zielke HR, Geschwind DH, Hof PR, Smith SM, Koch C, Grant SGN, Jones AR. 2012. An anatomically comprehensive atlas of the adult human brain transcriptome. Nature 489:391-399.

Henderson MX, Cornblath EJ, Darwich A, Zhang B, Brown H, Gathagan RJ, Sandler RM, Bassett DS, Trojanowski JQ, Lee VMY. 2019a. Spread of $\alpha$-synuclein pathology through the brain connectome is modulated by selective vulnerability and predicted by network analysis. Nat Neurosci 22:1248-1257.

Henderson MX, Trojanowski JQ, Lee VM-Y. 2019b. $\alpha$-Synuclein pathology in Parkinson's disease and related $\alpha$-synucleinopathies. Neurosci Lett 709:134316.

Hou X, Watzlawik JO, Fiesel FC, Springer W. 2020. Autophagy in Parkinson's Disease. J Mol Biol 
432:2651-2672.

Jubault T, Gagnon J-F, Karama S, Ptito A, Lafontaine A-L, Evans AC, Monchi O. 2011. Patterns of cortical thickness and surface area in early Parkinson's disease. Neuroimage 55:462-467.

Konno T, Ross OA, Puschmann A, Dickson DW, Wszolek ZK. 2016. Autosomal dominant Parkinson's disease caused by SNCA duplications. Parkinsonism Relat Disord 22 Suppl 1:S1-6.

Krishnan A, Williams LJ, McIntosh AR, Abdi H. 2011. Partial Least Squares (PLS) methods for neuroimaging: a tutorial and review. Neuroimage 56:455-475.

Laansma MA, Bright JK, Al-Bachari S, Anderson TJ, Ard T, Assogna F, Baquero KA, Berendse HW, Blair J, Cendes F, Dalrymple-Alford JC, Bie RMA, Debove I, Dirkx MF, Druzgal J, Emsley HCA, Garraux G, Guimarães RP, Gutman BA, Helmich RC, Klein JC, Mackay CE, McMillan CT, Melzer TR, Parkes LM, Piras F, Pitcher TL, Poston KL, Rango M, Ribeiro LF, Rocha CS, Rummel C, Santos LSR, Schmidt R, Schwingenschuh P, Spalletta G, Squarcina L, Heuvel OA, Vriend C, Wang J-J, Weintraub D, Wiest R, Yasuda CL, Jahanshad N, Thompson PM, Werf YD, The ENIGMA-Parkinson's Study. 2021. International multicenter analysis of brain structure across clinical stages of Parkinson's disease. Mov Disord. doi:10.1002/mds.28706

Lin X, Parisiadou L, Gu X-L, Wang L, Shim H, Sun L, Xie C, Long C-X, Yang W-J, Ding J, Chen ZZ, Gallant PE, Tao-Cheng J-H, Rudow G, Troncoso JC, Liu Z, Li Z, Cai H. 2009. Leucine-rich repeat kinase 2 regulates the progression of neuropathology induced by Parkinson's-disease-related mutant alpha-synuclein. Neuron 64:807-827.

Luk KC, Kehm V, Carroll J, Zhang B, O’Brien P, Trojanowski JQ, Lee VM-Y. 2012. Pathological $\alpha$-synuclein transmission initiates Parkinson-like neurodegeneration in nontransgenic mice. Science 338:949-953.

Markello RD, Misic B. 2021. Comparing spatial null models for brain maps. Neuroimage 236:118052.

Markello R, Shafiei G, Zheng Y-Q, Mišić B. 2020. abagen: A toolbox for the Allen Brain Atlas genetics data. doi:10.5281/zenodo.3726257

McCann H, Cartwright H, Halliday GM. 2016. Neuropathology of $\alpha$-synuclein propagation and braak hypothesis. Mov Disord 31:152-160.

McIntosh AR, Mišić B. 2013. Multivariate statistical analyses for neuroimaging data. Annu Rev Psychol 64:499-525.

Mi H, Muruganujan A, Casagrande JT, Thomas PD. 2013. Large-scale gene function analysis with the PANTHER classification system. Nat Protoc 8:1551-1566.

Miller KL, Alfaro-Almagro F, Bangerter NK, Thomas DL, Yacoub E, Xu J, Bartsch AJ, Jbabdi S, Sotiropoulos SN, Andersson JLR, Griffanti L, Douaud G, Okell TW, Weale P, Dragonu I, Garratt S, Hudson S, Collins R, Jenkinson M, Matthews PM, Smith SM. 2016. Multimodal population brain imaging in the UK Biobank prospective epidemiological study. Nat Neurosci 19:1523-1536.

Nalls MA, Blauwendraat C, Vallerga CL, Heilbron K, Bandres-Ciga S, Chang D, Tan M, Kia DA, Noyce AJ, Xue A, Bras J, Young E, von Coelln R, Simón-Sánchez J, Schulte C, Sharma M, Krohn L, Pihlstrøm L, Siitonen A, Iwaki H, Leonard H, Faghri F, Gibbs JR, Hernandez DG, Scholz SW, Botia JA, Martinez M, Corvol J-C, Lesage S, Jankovic J, Shulman LM, Sutherland M, Tienari P, Majamaa K, Toft M, Andreassen OA, Bangale T, Brice A, Yang J, Gan-Or Z, Gasser T, Heutink P, Shulman JM, Wood NW, Hinds DA, Hardy JA, Morris HR, Gratten J, Visscher PM, Graham RR, Singleton $\mathrm{AB}, 23 \mathrm{andMe}$ Research Team, System Genomics of Parkinson's Disease Consortium, International Parkinson's Disease Genomics Consortium. 2019. Identification of novel risk loci, causal insights, and heritable risk for Parkinson's disease: a meta-analysis of genome-wide association studies.

Lancet Neurol 18:1091-1102.

Neilson E, Shen X, Cox SR, Clarke T-K, Wigmore EM, Gibson J, Howard DM, Adams MJ, Harris MA, Davies G, Deary IJ, Whalley HC, McIntosh AM, Lawrie SM. 2019. Impact of Polygenic Risk for Schizophrenia on Cortical Structure in UK Biobank. Biol Psychiatry 86:536-544. 
Noyce AJ, Bandres-Ciga S, Kim J, Heilbron K, Kia D, Hemani G, Xue A, Lawlor DA, Smith GD, Duran R, Gan-Or Z, Blauwendraat C, Gibbs JR, 23andMe Research Team5, International Parkinson's Disease Genomics Consortium (IPDGC), Hinds DA, Yang J, Visscher P, Cuzick J, Morris H, Hardy J, Wood NW, Nalls MA, Singleton AB. 2019. The Parkinson's Disease Mendelian Randomization Research Portal. Mov Disord 34:1864-1872.

Parkinson Progression Marker Initiative. 2011. The Parkinson Progression Marker Initiative (PPMI). Prog Neurobiol 95:629-635.

Patel Y, Shin J, Drakesmith M, Evans J, Pausova Z, Paus T. 2020. Virtual histology of multi-modal magnetic resonance imaging of cerebral cortex in young men. Neuroimage 218:116968.

Paul KC, Schulz J, Bronstein JM, Lill CM, Ritz BR. 2018. Association of Polygenic Risk Score With Cognitive Decline and Motor Progression in Parkinson Disease. JAMA Neurol 75:360-366.

Pedersen KM, Marner L, Pakkenberg H, Pakkenberg B. 2005. No global loss of neocortical neurons in Parkinson's disease: a quantitative stereological study. Mov Disord 20:164-171.

Purcell S, Neale B, Todd-Brown K, Thomas L, Ferreira MAR, Bender D, Maller J, Sklar P, de Bakker PIW, Daly MJ, Sham PC. 2007. PLINK: a tool set for whole-genome association and population-based linkage analyses. Am J Hum Genet 81:559-575.

Rahayel S, Mišić B, Zheng Y-Q, Liu Z-Q, Abdelgawad A, Abbasi N, Caputo A, Zhang B, Lo A, Kehm V, Kozak M, Soo Yoo H, Dagher A, Luk KC. 2021a. Differentially targeted seeding reveals unique pathological alpha-synuclein propagation patterns. Brain. doi:10.1093/brain/awab440

Rahayel S, Postuma RB, Montplaisir J, Mišić B, Tremblay C, Vo A, Lewis S, Matar E, Ehgoetz Martens K, Blanc F, Yao C, Carrier J, Monchi O, Gaubert M, Dagher A, Gagnon J-F. 2021b. A Prodromal Brain-Clinical Pattern of Cognition in Synucleinopathies. Ann Neurol 89:341-357.

Rakic P, Ayoub AE, Breunig JJ, Dominguez MH. 2009. Decision by division: making cortical maps. Trends Neurosci 32:291-301.

Raunio A, Kaivola K, Tuimala J, Kero M, Oinas M, Polvikoski T, Paetau A, Tienari PJ, Myllykangas L. 2019. Lewy-related pathology exhibits two anatomically and genetically distinct progression patterns: a population-based study of Finns aged 85. Acta Neuropathologica. doi:10.1007/s00401-019-02071-3

Schulz-Schaeffer WJ. 2010. The synaptic pathology of alpha-synuclein aggregation in dementia with Lewy bodies, Parkinson's disease and Parkinson's disease dementia. Acta Neuropathol 120:131-143.

Seidlitz J, Nadig A, Liu S, Bethlehem RAI, Vértes PE, Morgan SE, Váša F, Romero-Garcia R, Lalonde FM, Clasen LS, Blumenthal JD, Paquola C, Bernhardt B, Wagstyl K, Polioudakis D, de la Torre-Ubieta L, Geschwind DH, Han JC, Lee NR, Murphy DG, Bullmore ET, Raznahan A. 2020. Transcriptomic and cellular decoding of regional brain vulnerability to neurogenetic disorders. Nat Commun 11:3358.

Senkevich K, Gan-Or Z. 2020. Autophagy lysosomal pathway dysfunction in Parkinson's disease; evidence from human genetics. Parkinsonism Relat Disord 73:60-71.

Shafiei G, Markello RD, Makowski C, Talpalaru A, Kirschner M, Devenyi GA, Guma E, Hagmann P, Cashman NR, Lepage M, Chakravarty MM, Dagher A, Mišić B. 2020. Spatial Patterning of Tissue Volume Loss in Schizophrenia Reflects Brain Network Architecture. Biol Psychiatry 87:727-735.

Shin J, French L, Xu T, Leonard G, Perron M, Pike GB, Richer L, Veillette S, Pausova Z, Paus T. 2018. Cell-Specific Gene-Expression Profiles and Cortical Thickness in the Human Brain. Cereb Cortex 28:3267-3277.

Soukup S-F, Vanhauwaert R, Verstreken P. 2018. Parkinson's disease: convergence on synaptic homeostasis. EMBO J 37. doi:10.15252/embj.201898960

Sudlow C, Gallacher J, Allen N, Beral V, Burton P, Danesh J, Downey P, Elliott P, Green J, Landray M, Liu B, Matthews P, Ong G, Pell J, Silman A, Young A, Sprosen T, Peakman T, Collins R. 2015. UK biobank: an open access resource for identifying the causes of a wide range of complex diseases of 
middle and old age. PLoS Med 12:e1001779.

Tremblay C, Rahayel S, Vo A, Morys F, Shafiei G, Abbasi N, Markello RD, Gan-Or Z, Misic B, Dagher A. 2021. Brain atrophy progression in Parkinson's disease is shaped by connectivity and local vulnerability. Brain Commun 3:fcab269.

Vidal-Pineiro D, Parker N, Shin J, French L, Grydeland H, Jackowski AP, Mowinckel AM, Patel Y, Pausova Z, Salum G, Sørensen Ø, Walhovd KB, Paus T, Fjell AM, Alzheimer's Disease Neuroimaging Initiative and the Australian Imaging Biomarkers and Lifestyle flagship study of ageing. 2020. Cellular correlates of cortical thinning throughout the lifespan. Sci Rep 10:21803.

Winkler AM, Kochunov P, Blangero J, Almasy L, Zilles K, Fox PT, Duggirala R, Glahn DC. 2010. Cortical thickness or grey matter volume? The importance of selecting the phenotype for imaging genetics studies. Neuroimage 53:1135-1146.

Yau Y, Zeighami Y, Baker TE, Larcher K, Vainik U, Dadar M, Fonov VS, Hagmann P, Griffa A, Mišić B, Collins DL, Dagher A. 2018. Network connectivity determines cortical thinning in early Parkinson's disease progression. Nat Commun 9:12.

Yeo BTT, Krienen FM, Sepulcre J, Sabuncu MR, Lashkari D, Hollinshead M, Roffman JL, Smoller JW, Zöllei L, Polimeni JR, Fischl B, Liu H, Buckner RL. 2011. The organization of the human cerebral cortex estimated by intrinsic functional connectivity. J Neurophysiol 106:1125-1165.

Zeighami Y, Fereshtehnejad S-M, Dadar M, Collins DL, Postuma RB, Mišić B, Dagher A. 2019. A clinical-anatomical signature of Parkinson's disease identified with partial least squares and magnetic resonance imaging. Neuroimage 190:69-78.

Zeighami Y, Ulla M, Iturria-Medina Y, Dadar M, Zhang Y, Larcher KM-H, Fonov V, Evans AC, Louis Collins D, Dagher A. 2015. Network structure of brain atrophy in de novo Parkinson's disease. eLife. doi:10.7554/elife.08440

Zheng Y-Q, Zhang Y, Yau Y, Zeighami Y, Larcher K, Misic B, Dagher A. 2019. Local vulnerability and global connectivity jointly shape neurodegenerative disease propagation. PLoS Biol 17:e3000495. 
Tables

\begin{tabular}{lccc}
\hline GO term & Biological process & P-value & Fold \\
& $($ bnf $)$ & enrichment
\end{tabular}

GOrilla platform

GO:0007166 Cell surface receptor signaling pathway $\quad 0.01 \quad 1.4$

GO:0044281 Small molecule metabolic process $\quad 0.03 \quad 1.43$

$\begin{array}{llll}\text { GO:0003008 } & \text { System process } & 0.047 & 1.52\end{array}$

$\begin{array}{llll}\text { GO:0023051 } & \text { Regulation of signaling } & 0.048 & 1.27\end{array}$

\section{PANTHER}

platform

GO:0007166 Cell surface receptor signaling pathway $\quad 0.005 \quad 1.44$

GO:0007165 Signal transduction $\quad 0.01 \quad 1.26$

$\begin{array}{llll}\text { GO:0023052 Signaling } & 0.004 & 1.26\end{array}$

$\begin{array}{llll}\text { GO:0007154 Cell communication } & 0.01 & 1.25\end{array}$

$\begin{array}{llll}\text { GO:0050896 } & \text { Response to stimulus } & 0.048 & 1.17\end{array}$

Table 1. Gene ontology (GO) enrichment analysis of the genes associated with PD-PRS related cortical thinning. 


\begin{tabular}{|c|c|c|c|}
\hline Behavior/Habit & $\mathbf{N}$ & T-value & $\begin{array}{c}\text { P-value } \\
\text { (fdr) }\end{array}$ \\
\hline $\begin{array}{c}\text { Smoking cigarette } \\
\text { Pack/year }\end{array}$ & 134,861 & -3.48 & 0.001 \\
\hline $\begin{array}{l}\text { Alcohol intake frequency } \\
\text { Daily or almost daily } \\
\text { Three or four times a week } \\
\text { Once or twice a week } \\
\text { Three times a month } \\
\text { Social occasions only } \\
\text { Never }\end{array}$ & 142,516 & -4.08 & $2.07 e-04$ \\
\hline $\begin{array}{r}\text { Coffee intake } \\
\text { Cups/day }\end{array}$ & 448,360 & 1.04 & 0.31 \\
\hline $\begin{array}{c}\text { Sleep duration } \\
\text { Hours/day }\end{array}$ & 446,714 & 2.77 & 0.01 \\
\hline $\begin{array}{c}\text { Body mass index } \\
\mathrm{Kg} / \mathrm{m}^{2}\end{array}$ & 448,461 & -4.01 & $2.07 e-04$ \\
\hline $\begin{array}{l}\text { Educational attainment } \\
\text { College or university degree } \\
\text { A levels/AS levels or equivalent } \\
\text { O levels/GCSEs or equivalent } \\
\text { CSEs or equivalent } \\
\text { NVQ or HND or HNC or equivalent } \\
\text { Other professional qualifications e.g., nursing, } \\
\text { teaching } \\
\text { None of the above }\end{array}$ & 449,137 & 1.53 & 0.17 \\
\hline $\begin{array}{l}\text { Fluid intelligence } \\
\text { Number of correct answers given to the fluid } \\
\text { intelligence questions }\end{array}$ & 147,365 & 1.01 & 0.31 \\
\hline
\end{tabular}

Table 2. Behavioral correlates of genetic risk for PD. N; sample size for the analysis. fdr: false discovery rate corrected $p$-value. 


\begin{tabular}{|c|c|c|c|}
\hline SNP & Nearest Gene & QTL Nominated Gene & $\mathbf{P}$, all studies \\
\hline rs356182 & SNCA & SNCA & $3.89 E-154$ \\
\hline rs356203 & SNCA & & 5.16E-149 \\
\hline rs34637584 & LRRK2 & LRRK2 & $3.61 \mathrm{E}-148$ \\
\hline rs35749011 & KRTCAP2 & & 1.72E-70 \\
\hline rs34311866 & TMEM175 & TMEM175 & 9.98E-70 \\
\hline rs62053943 & CRHR1 & WNT3 & 3.58E-68 \\
\hline rs199453 & NSF & & 8.62E-67 \\
\hline rs356228 & SNCA & & $9.53 E-49$ \\
\hline rs7225002 & KANSL1 & & $1.84 \mathrm{E}-40$ \\
\hline rs1474055 & STK39 & STK39 & $2.54 \mathrm{E}-39$ \\
\hline rs7221167 & MAPT-AS1 & & $1.36 \mathrm{E}-37$ \\
\hline rs10847864 & HIP1R & HIP1R & $1.47 \mathrm{E}-37$ \\
\hline rs5019538 & SNCA & SNCA & 1.13E-36 \\
\hline rs10513789 & MCCC1 & MCcC1 & $1.22 E-34$ \\
\hline rs823118 & NUCKS1 & NUCKS1 & $1.11 \mathrm{E}-29$ \\
\hline rs76904798 & LRRK2 & LRRK2 & $1.52 E-28$ \\
\hline rs4698412 & BST1 & BST1 & $2.06 \mathrm{E}-28$ \\
\hline rs117896735 & INPP5F & SEC23IP & $2.36 \mathrm{E}-28$ \\
\hline rs112485576 & HLA-DRB5 & HLA-DRB5 & $6.96 \mathrm{E}-28$ \\
\hline rs17686238 & MAP3K14 & & 8.25E-27 \\
\hline rs199351 & GPNMB & GPNMB & 5.25E-26 \\
\hline rs1867598 & ELOVL7 & ELOVL7 & $2.52 \mathrm{E}-23$ \\
\hline rs12456492 & RIT2 & & $3.80 \mathrm{E}-23$ \\
\hline rs76763715 & GBAP1 & GBAP1 & 1.59E-22 \\
\hline
\end{tabular}

Table 3. Top genes from the PD GWAS, taken from Table S2 of Nalls et al. (2019). Rows in red indicate genes whose function is related to the autophagy-lysosomal pathway. Duplicate genes in light gray. SNP: single nucleotide polymorphism. QTL: quantitative trait locus. 


\section{Thickness}

a

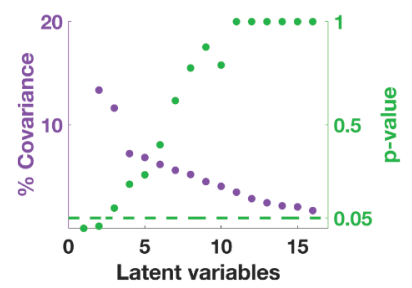

b

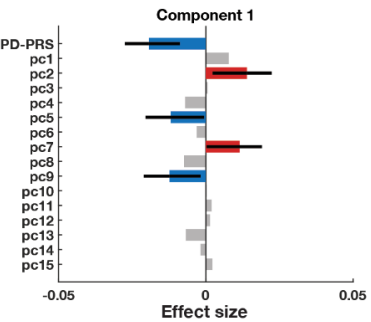

C

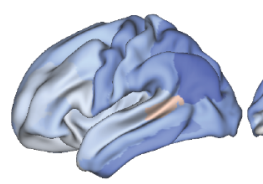

Significant PD PRS effect

d

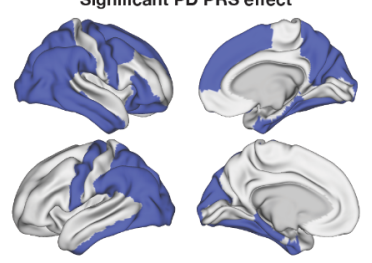

Surface Area

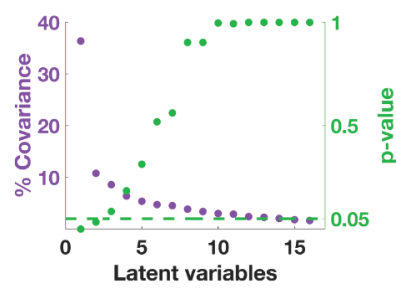

g

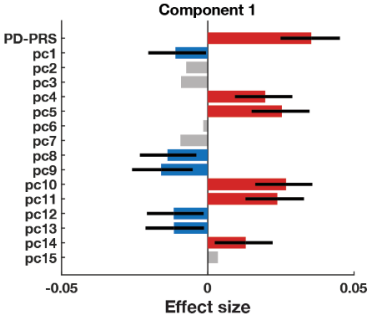

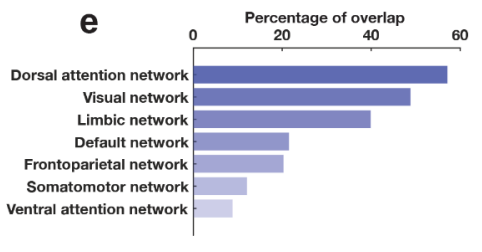

h

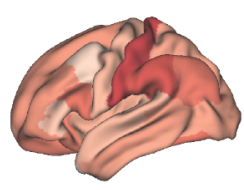

i

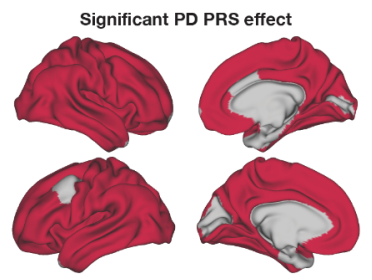

t-value
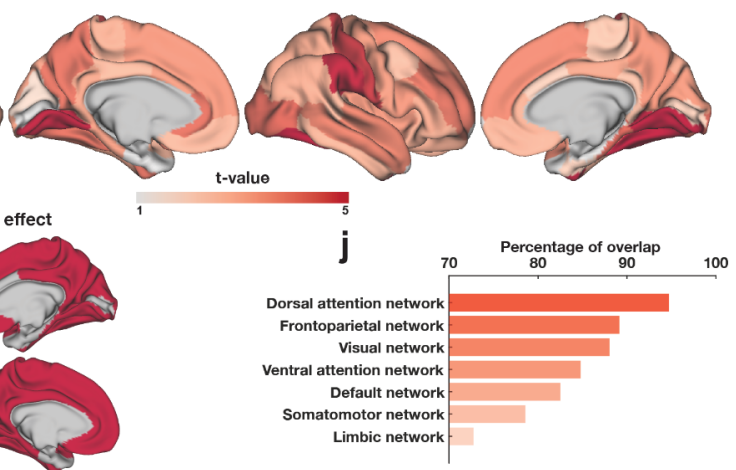

Fig. 1: Association between PD-PRS and cortical thickness and surface area. (a, f) Covariance explained and permutation p-values for latent variables identified from the PLS analysis between genetic components and thickness and surface area, respectively. PC1-PC15 are the first 15 principal components reflecting population stratification $(\mathbf{b}, \mathbf{g})$ The effect size estimates of the genetic components in explaining variance observed in cortical measurements, derived from the SVD analysis of the first latent variable. Confidence intervals are calculated by bootstrap testing. (c, h) T-statistic maps of the cortical effects of PD-PRS. (d, i) Parcels with significant effect of PD-PRS corrected for multiple comparisons. (e, j) Distribution of PD-PRS effects in the 7 Yeo intrinsic networks for thickness and surface area, respectively. 
a

DBM Year 2 - baseline
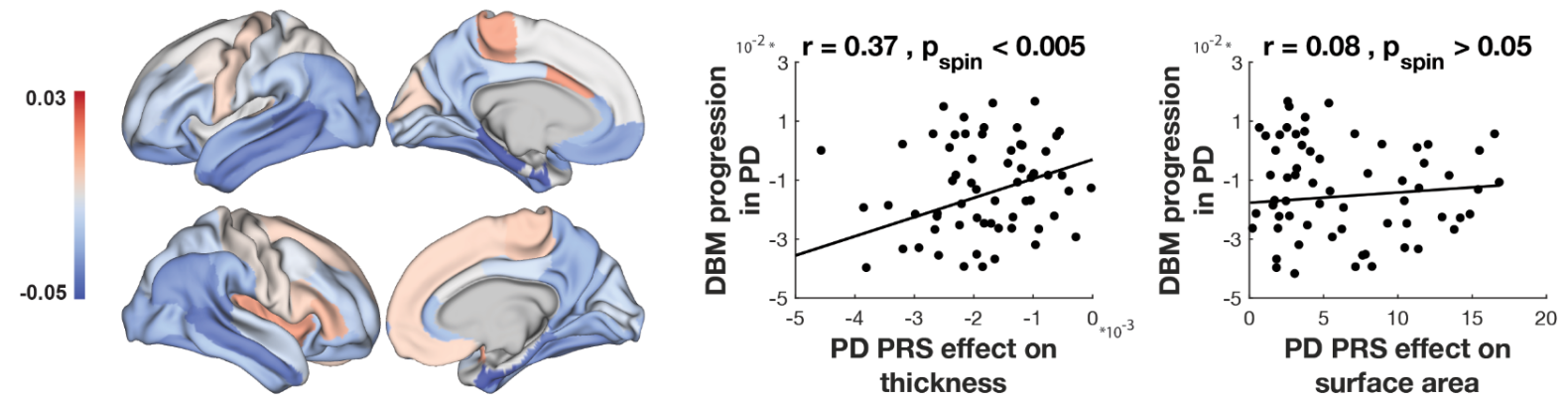

DBM Year 4 - baseline
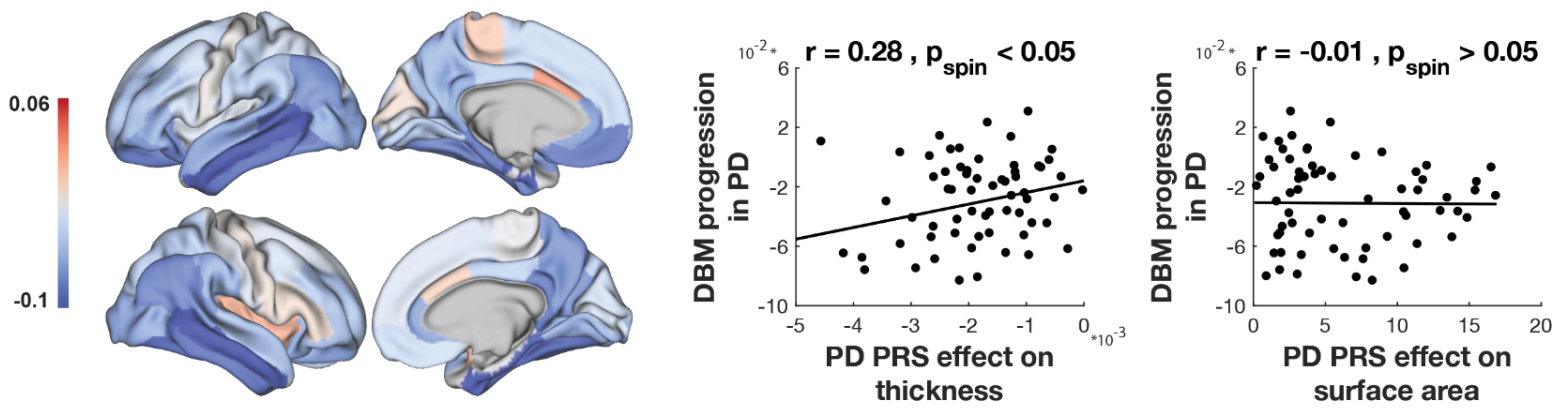

b
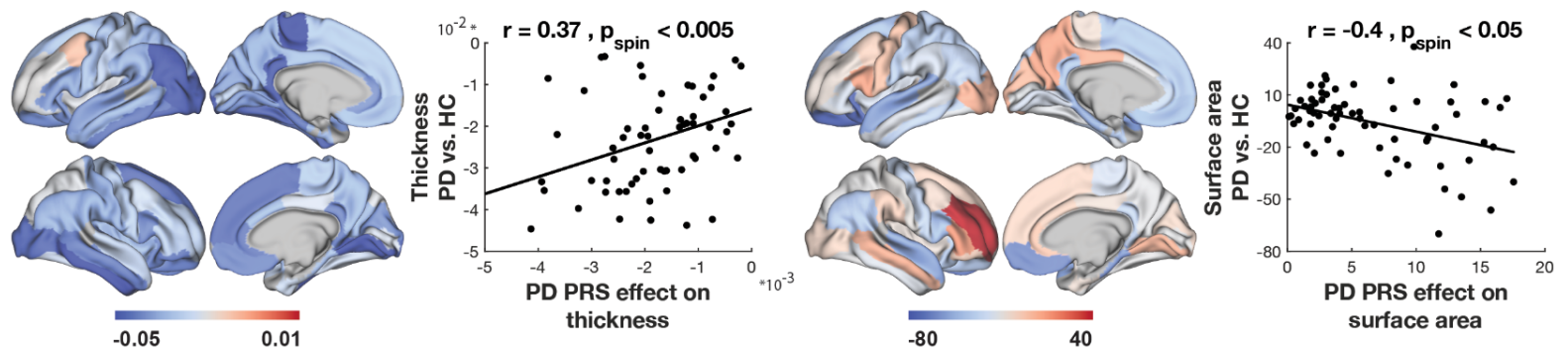

C

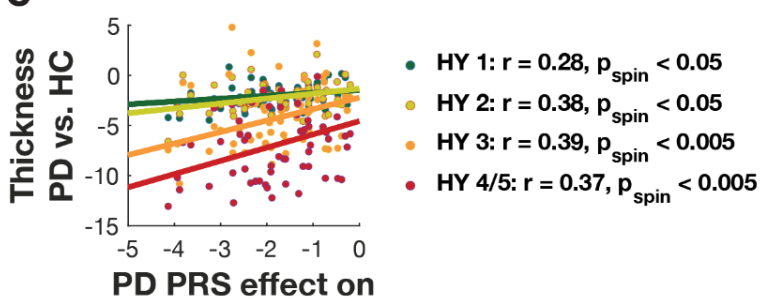

thickness

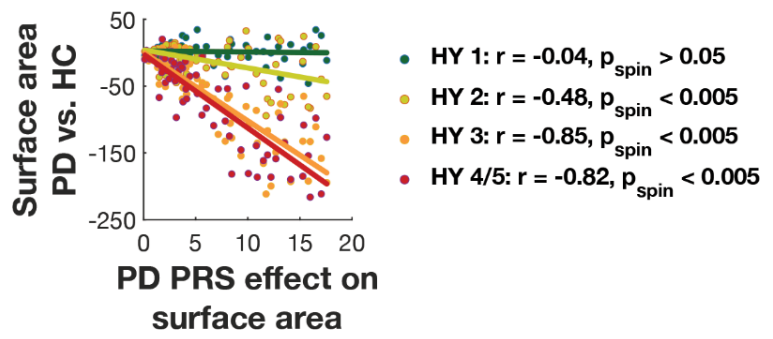

Fig. 2: Comparison of PD-PRS effect and Parkinson's disease cortical atrophy distribution. Correlation of PD-PRS influence maps for thickness and surface area with: (a) PD DBM progression maps after 2 years and 4 years of follow-up from PPMI, and (b) cortical thickness and surface area (PD-controls) from ENIGMA. (c) Effect of Hoehn and Yahr stage on the correlations in panel b. Brain maps present region-wise correlation coefficient estimates. DBM = deformation-based morphometry; $r=$ correlation coefficient; $p_{\text {spin }}=p$-values obtained after multiple comparison correction and spin tests; HY = Hoehn \& Yahr stage. 

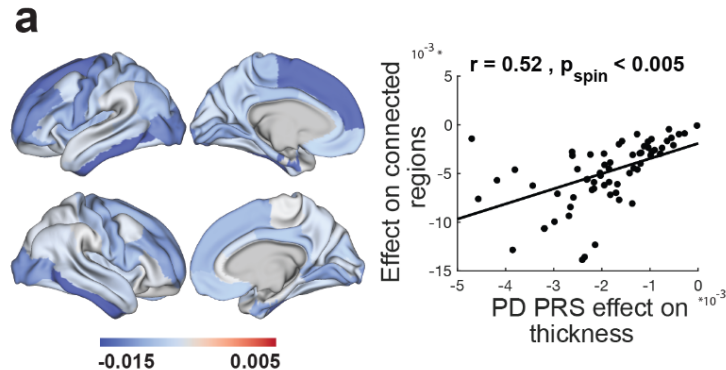

b
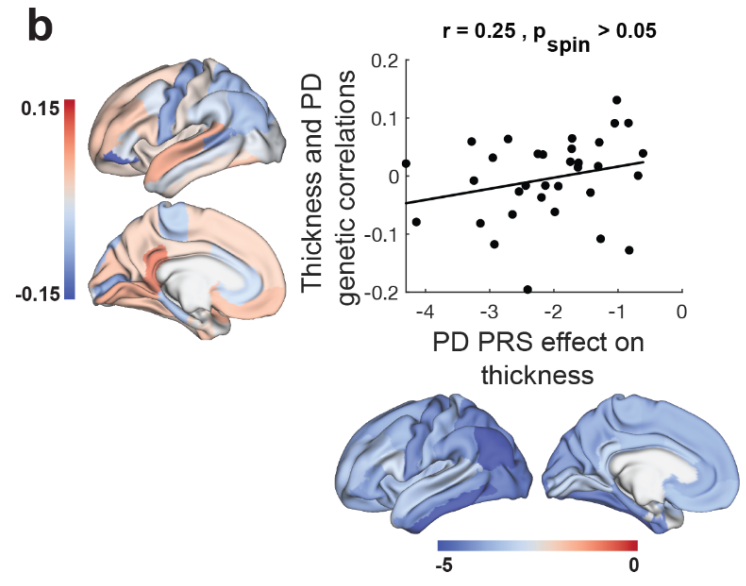
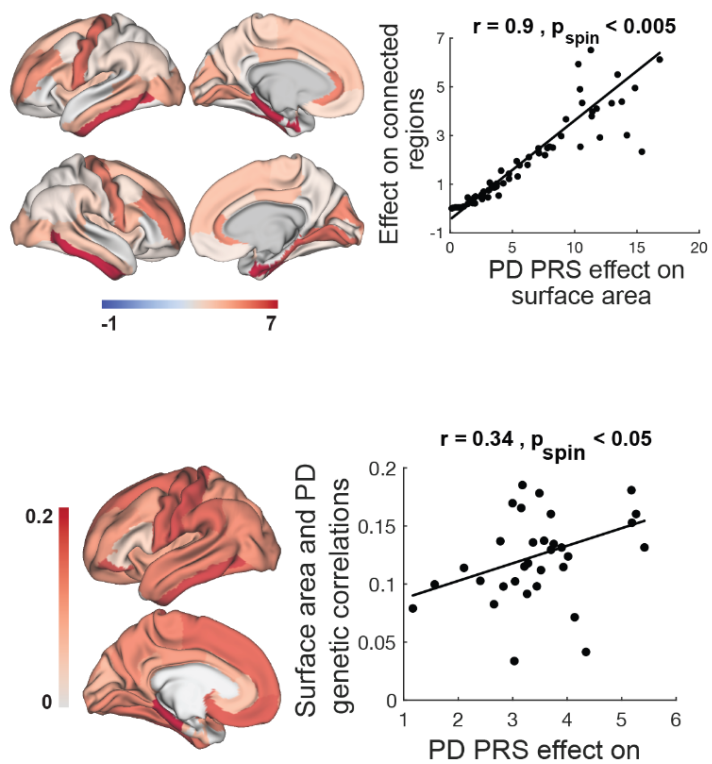

surface area

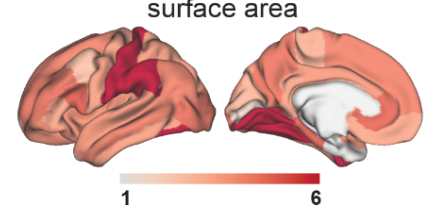

C
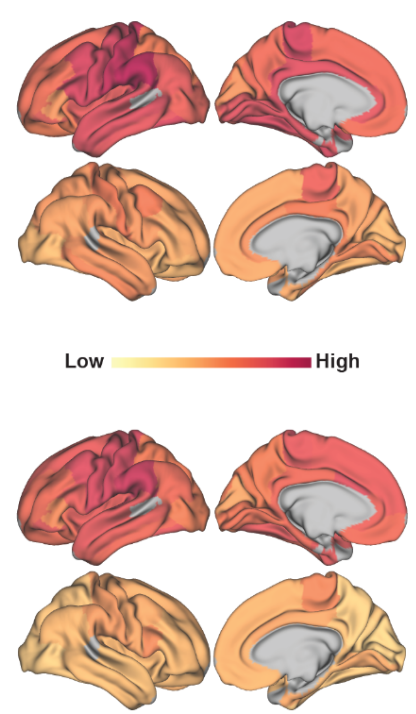

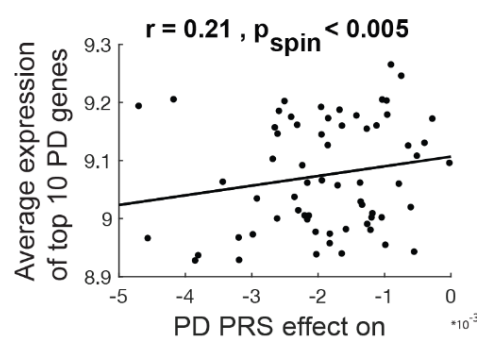

thickness

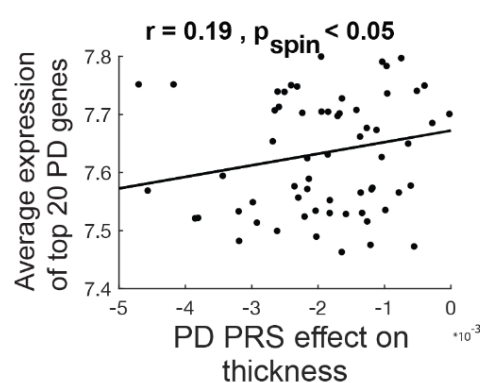

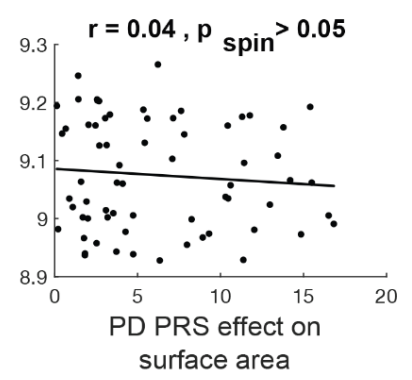

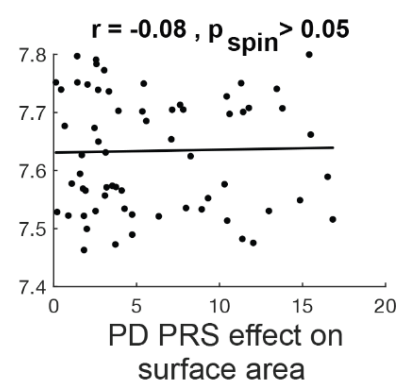

Fig. 3: Comparison of PD-PRS effect with other cortical maps. Correlation of PD-PRS influence maps for thickness and surface area with (a) the same measure in connected regions, (b) maps of genetic correlations between cortical thickness/area and PD (Grasby et al., 2020), and (c) cortical expression patterns of the genes near the PD top ten (top row) and top twenty (bottom row) most significant single nucleotide polymorphisms of the GWAS. Gene expression maps derived from the Allen Human Brain Atlas. $r=$ correlation coefficient; $p_{\text {spin }}=$ p-values obtained after multiple comparison correction and spin test. 


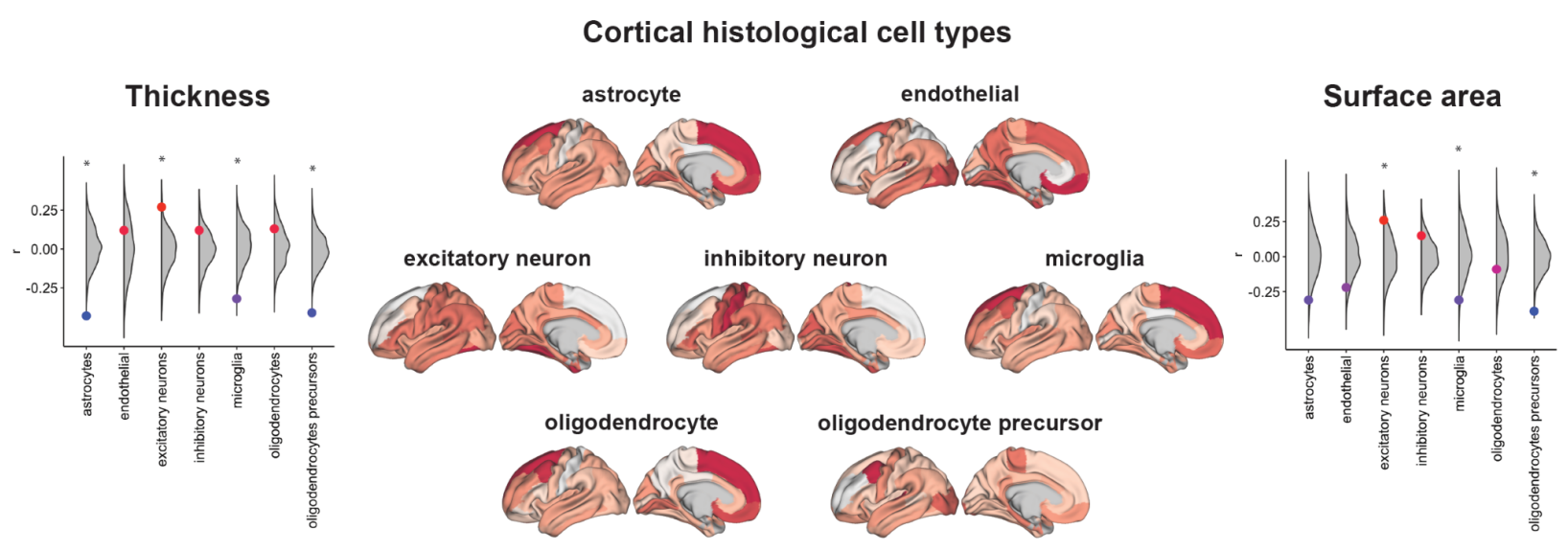

Fig. 4: Relation between PD-PRS effect and cortical histological cell type distribution. Correlation of PD-PRS profile maps for thickness and surface area with prevalence of specific cell types in the cortex. The maps in the centre panel are derived from Seidlitz et al. (2020). $r=$ correlation coefficient. $*=$ significant correlation after FDR multiple comparison correction (i.e., corrected p-value $<0.05$ ).

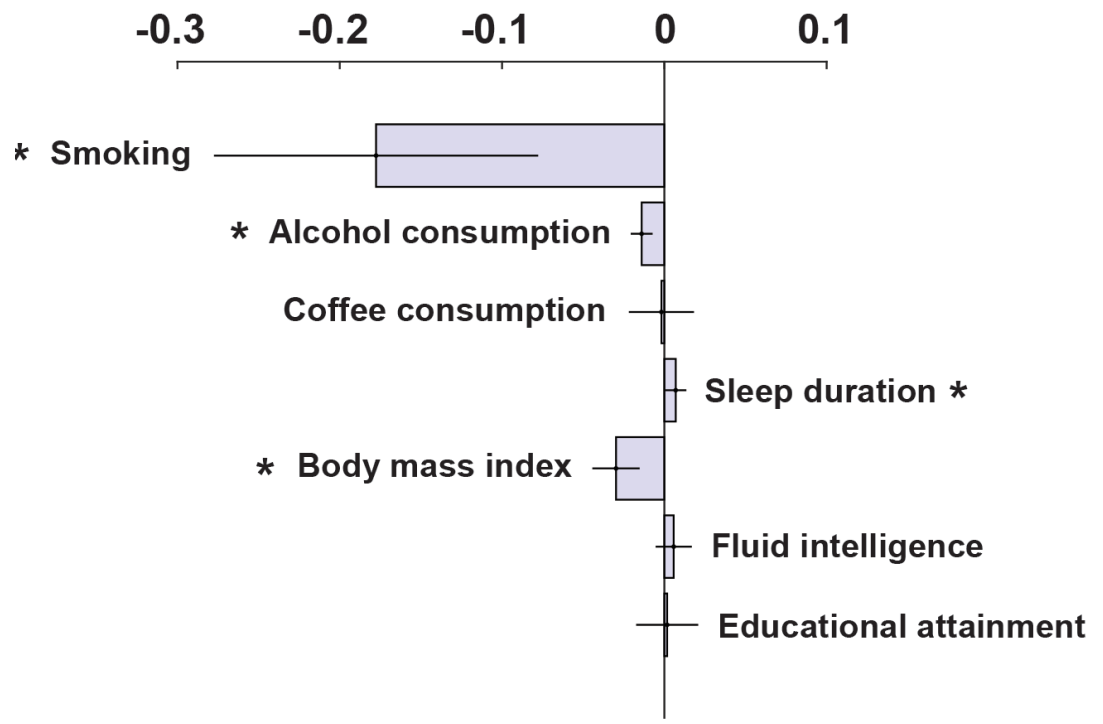

Fig. 5: Genetic correlations. Correlation between PD-PRS and characteristic PD phenotypes in healthy participants of the UKBB (see Table 2). T-statistics are displayed. * = significant correlation after multiple comparison correction (i.e., corrected p-value $<0.05$ ). 